\title{
Methodology of an International Study of People with Multiple Sclerosis Recruited through Web 2.0 Platforms: Demographics, Lifestyle, and Disease Characteristics
}

\author{
Emily J. Hadgkiss, ${ }^{1}$ George A. Jelinek, ${ }^{1,2}$ Tracey J. Weiland, ${ }^{1,3}$ Naresh G. Pereira, ${ }^{4}$ \\ Claudia H. Marck, ${ }^{1}$ and Dania M. van der Meer ${ }^{1}$ \\ ${ }^{1}$ Emergency Practice Innovation Centre, St Vincent's Hospital, Melbourne, VIC 3065, Australia \\ ${ }^{2}$ Department of Epidemiology and Preventive Medicine, Monash University, Melbourne, VIC 3004, Australia \\ ${ }^{3}$ Department of Medicine, The University of Melbourne (St Vincent's Hospital), Melbourne, VIC 3065, Australia \\ ${ }^{4}$ Faculty of Medicine, The University of Notre Dame Australia, Fremantle, WA 6959, Australia \\ Correspondence should be addressed to Emily J. Hadgkiss; emily.hadgkiss@svhm.org.au
}

Received 20 December 2012; Revised 27 February 2013; Accepted 20 March 2013

Academic Editor: B. R. Ott

Copyright (C) 2013 Emily J. Hadgkiss et al. This is an open access article distributed under the Creative Commons Attribution License, which permits unrestricted use, distribution, and reproduction in any medium, provided the original work is properly cited.

\begin{abstract}
Background. Despite evidence of the potential importance of the role of health and lifestyle behaviours in multiple sclerosis (MS) outcomes, there has not been a significant focus on this area of research. Aim. We aimed to recruit an international sample of people with MS at baseline and over a five-year timeframe, examine their health and lifestyle behaviours, and determine the relationship of these behaviours to self-reported disability, disease activity, and quality of life. Methods. People with MS were recruited through web 2.0 platforms including interactive websites, social media, blogs, and forums and completed a comprehensive, multifaceted online questionnaire incorporating validated and researcher-derived tools. Results. 2519 participants met inclusion criteria for this study. This paper describes the study methodology in detail and provides an overview of baseline participant demographics, clinical characteristics, summary outcome variables, and health and lifestyle behaviours. The sample described is unique due to the nature of recruitment through online media and due to the engagement of the group, which appears to be well informed and proactive in lifestyle modification. Conclusion. This sample provides a sound platform to undertake novel exploratory analyses of the association between a variety of lifestyle factors and MS outcomes.
\end{abstract}

\section{Introduction}

Multiple sclerosis (MS) is a chronic, debilitating neurological condition that affects an estimated two million people worldwide. Despite decades of research, the aetiology of MS and factors that affect disease progression and relapse rate are still debated [1]. Symptoms of the disease are heterogeneous, and the current goal of therapeutic intervention is to slow the progression of disability and provide symptomatic relief.

Several large national MS registries collect longitudinal data on patient outcomes and measure the effectiveness of a range of therapies [2]. Epidemiological studies that utilise these data are a cost-effective way of exploring associations between factors that influence relapse rate or disease progression. There is a comprehensive body of the literature supporting a relationship between lifestyle and psychosocial factors, and MS health outcomes [3-8]. Despite this expanding body of research, little is known about the degree to which beneficial lifestyle modification is adopted by the international MS community and whether this has a positive impact on health outcomes. To our knowledge, none of these registries collect comprehensive data on lifestyle factors.

We aimed to recruit followers of online media engaging people with MS and examine in detail their health and lifestyle behaviours and determine the relationship of these factors to self-reported disability, disease activity, and quality of life, with a follow-up period of five years. For many people with chronic diseases, the internet is an important tool for self-education, emotional support, and practical advice from people facing similar challenges [9]. Web 2.0 platforms like 
Facebook, Twitter, forums, and blogs are powerful tools that enable patients to develop greater self-efficacy [10]. Specifically, MS resources encompass an extensive online presence [11]. We aimed to recruit people to our study through these platforms as this enabled us to gather a sample of people with MS containing many who are making lifestyle and other risk-modifying changes, thereby allowing comparison between patients with a range of different approaches to selfmanagement. We also suspected that many online patients are highly proactive and have an interest in self-help and lifestyle modification, offering a different perspective to the more traditional approaches to studying treatment, currently assessed in national registries.

This study provides a snapshot of current lifestyle and risk-modifying behaviours of a large international group of people with MS, as well as an ongoing platform for analysing the association between these variables and disease progression, that have not previously been examined in detail. They will also help to inform future research, and people with MS, of the potential contribution of lifestyle to their health-related quality of life, disease activity, and physical disability. This paper reports in detail the methodology of the study and an overview of the characteristics of participants recruited. Future studies will seek to analyse and report associations between lifestyle variables and disease data in detail.

\section{Materials and Methods}

2.1. Participants and Data Collection. This survey, collecting the baseline data for the health outcomes and lifestyle interventions in a sample of people with multiple sclerosis (HOLISM) study, was conducted using the online software SurveyMonkey. A webpage was created, inviting people to take part in the study, with a description of the study aims. Online recruitment for the study took place over a 15-week period, using websites, a mailing list, and web 2.0 platforms such as blogs, forums, Facebook, and Twitter. The principle investigator (GJ) had developed an online presence in the MS community over the 12 years prior to the study due to his extensive work advocating for lifestyle modification and integrated MS management, including moderating a website dedicated to this field (http://www.overcomingmultiplesclerosis.org; "OMS”). Two members of the research team (GJ and EH) systematically identified Facebook groups and pages with over 500 members or followers, designed for people with MS. On a weekly, or biweekly basis (depending on site traffic), the researchers invited people with MS to take part in the study and posted a link to the survey. Members of the OMS website were informed of the study by email and invited to participate. This was followed up with several reminders over the course of the recruitment period. Moderators of several popular MS blogs were contacted and asked to post information about the survey on their websites. Several MS societies were emailed and asked to promote the study through their websites or social media. The response to these requests was positive, and many people continued to voluntarily promote the study through their own online networks, contacts, and communities, creating a snowball effect.
The survey webpage linked individuals to a participant information sheet, which they were asked to read before giving consent. This was required for continued participation in the survey. Anyone formally diagnosed with MS by a medical doctor was encouraged to take part, but participants were excluded if they were under 18 years of age. This was verified in the survey: if the year of birth selected indicated that they were under 18 years of age, skip logic took the participant to the end of the survey. All participants were required to complete their contact details to facilitate followup. Data were stored in a reidentifiable form, and data security measures were undertaken to ensure that only members of the research team had access to participant information. The research team was available to answer participants' questions by phone and email. Ethics approval was granted by St Vincent's Hospital Melbourne Human Research Ethics Committee (LRR 055/12).

2.2. Data Collection and Tools. The survey consisted of a maximum of 163 questions, taking around 40 minutes to complete, although skip logic enabled participants to avoid some questions not relevant to them. Three members of the research team searched and reviewed validated tools for use in the survey. Where possible, a tool was chosen that was psychometrically sound and had been tested in a similar study (Table 1). Some questions were unique to the domains assessed, in particular lifestyle variables that had not been extensively investigated, and hence validated questions or tools were not available. These included items on sun exposure, vitamin D supplementation, Omega-3 supplementation, and meditation and stress reduction practices. Responses were usually multiple choice and categorised to reduce respondent error through free-text numerical response. Such items were developed by the research team with consideration of studies that examined similar outcome variables. For any anthropometric or other measures, units utilised across different countries were considered. Although participants were encouraged to answer all questions, only completion of contact details was compulsory. Many of the items had been piloted already with a cohort of people with MS (manuscript in preparation) related to a longitudinal study [6]. The survey was piloted online with seven people with MS, and minor alterations were made based on their feedback.

The survey consisted of the following domains.

Sociodemographics. This domain consisted of items collecting data on age, gender, current location, country of birth, parents' countries of birth, cultural background, marital status, number of children, employment, education, height, and weight. All sociodemographic items were multiple choice. Cultural background was categorised according to the Australian standard classification of cultural and ethnic groups [20], with an additional free-text "other" response available.

Diagnostic History. This included confirmation of MS diagnosis by a medical doctor, year of diagnosis, first year of symptoms, diagnostic investigations undertaken, number of brain and spinal lesions, and subtype of MS on diagnosis/currently. Some of these items were modified from the North American 
TABLE 1: Summary of validated tools used.

\begin{tabular}{lccc}
\hline Outcome variable & Instrument (reference) & Number of items & Authors (reference) \\
\hline Disability & Patient determined disease steps (PDDS) & 1 & Hohol et al., 1995 [12] \\
Comorbidities & Self-administered comorbidity questionnaire (SCQ) & 13 & Sangha et al., 2003 [13] \\
Health-related quality of life & Multiple sclerosis quality of life-54 (MSQOL-54) & 54 & Vickrey et al., 1995 [14] \\
Dietary habits & Diet habits questionnaire (DHQ), modified & 20 & McKellar et al., 2008 [15] \\
Physical activity & International physical activity questionnaire (IPAQ) & 7 & Craig et al., 2003 [16] \\
Social support & Single item measure of social support (SIMSS) & 1 & Blake and McKay, 1986 [17] \\
Fatigue & Fatigue severity scale (FSS) & 9 & Krupp et al., 1989 [18] \\
Depression & Patient health questionnaire short version (PHQ-2) & 2 & Kroenke et al., 2003 [19] \\
\hline
\end{tabular}

Research Committee on Multiple Sclerosis (NARCOMS) enrolment questionnaire. Although only people with a formal diagnosis of MS were invited to participate, to improve the validity of self-report, those who could not confirm their diagnosis but had clinically isolated syndrome or "possible MS" were still able to complete the questionnaire. However, for the purpose of this paper, analyses were only performed for those self-reporting a confirmed diagnosis of MS.

Disease Activity. This was determined through participant's reported relapse rate (self-diagnosed using the definition of a relapse as provided in the NARCOMS enrolment questionnaire; and physician-diagnosed) in the last 12 months and the last 5 years; number of relapses treated with steroids and whether currently experiencing symptoms due to recent relapse. A five-year annualised relapse rate was derived by dividing the number of relapses over five years by the number of years of disease with an upper limit of five.

Level of Disability. The patient-determined disease steps (PDDS; Table 1) is a self-reported surrogate tool to the expanded disability status scale (EDSS) which is commonly used by neurologists to assess gait disability [12]. It is scored ordinally from 0 (normal) to 8 (bed bound). It is simple and easy to administer, correlates well with the EDSS and moderately with the widely used multiple sclerosis functional composite, and has excellent concordance between raters. It is also deemed a practical tool to use to assess changes in disability over time [21]. The PDDS has been used in a number of studies associated with the NARCOMS registry [22-24].

Comorbidities. The self-administered comorbidity questionnaire (SCQ) is an efficient method of assessing the presence of comorbidities in the absence of medical record review [13]. It also determines whether treatment is received and if the condition limits activities. It correlates modestly with the Charlson comorbidity index and has been used in a study of participants with MS [25]. For the purpose of this study, two arthritic conditions were combined into one, and due to anticipated high prevalence, anxiety was also listed as a condition.

Health-Related Quality of Life. The multiple sclerosis quality of life-54 (MSQOL-54) is a measure of health-related quality of life (HRQOL) that was developed from the RAND 36-item health survey (SF-36) and supplemented with 18 additional items. The MSQOL-54 consists of 52 items distributed into 12 scales and two single items, which give rise to two composite scores-the physical and mental health composites. Internal consistency reliability estimates for the 12 multi-item scales ranged from 0.75 to 0.96 in a sample of 179 patients with multiple sclerosis [14]. Test-retest intraclass correlation coefficients ranged from 0.66 to 0.96 , and construct validity has been shown to be strong. The tool has since been extensively validated and translated in international populations [26-28], and in assessing the impact of fatigue [29], depression [30], and sexual dysfunction [31], as well as a number of medical therapies.

Dietary Habits. The diet habits questionnaire (DHQ) is a 22-item dietary assessment tool, validated in an Australian cardiac disease population [15]. It assesses saturated and nonsaturated fat intake, fruit and vegetable, fibre, takeaway, snack habits, and omega-3 consumption, among other estimates. To reduce respondent burden, we elected for a brief dietary screening tool over a more elaborate food diary or food frequency questionnaire. Shorter, nutrient-specific, semiquantitative questionnaires were not appropriate for our study, which aimed to assess diet more broadly.

Smoking and Alcohol. Frequency and number of alcoholic drinks were measured with examples of a standard drink provided. Other items were current smoking status, number of cigarettes smoked, and year quit, if previously smoked.

Medication Use. A list of 24 disease modifying drugs (DMDs) and other common MS medications including generic and trade names were provided, and participants were asked to indicate current and previous use, including length of time taken. In addition, participants were asked to indicate whether they took prescription, over-the-counter, or herbal agents for 10 symptomatic conditions: depression, anxiety, headaches, other pain, fatigue, difficulty sleeping, bladder problems, bowel problems, spasticity, and "other".

Sunlight and Vitamin D. A total of seven researcher-devised items explored participants' average weekly frequency of sun exposure, current vitamin D supplementation and dosage, serum vitamin $\mathrm{D}$ level, and recency of test. Adequate sun exposure was considered to be 10-15 minutes of sunlight on a day with UV index of 7 (more or less if the UV index is lower or higher). 
Omega-3. Items included both the type and daily dosage of omega-3 supplementation used on average in the last 12 months. Types of omega-3 included fish oil, high strength fish oil, flaxseed oil, and "other" free-text responses.

Exercise. The international physical activity questionnaire (IPAQ) is a 7-day recall of frequency and duration of vigorous and moderate activity participation: walking and sitting [16]. Items can be scored separately, as a combined total score, or computed as metabolic equivalent of task (MET) minutes. It has been validated in a number of studies and population groups globally, including MS populations [32, 33].

Stress Management. Four researcher-devised items measured the weekly frequency and length of meditation practice undertaken on average over the previous 12 months, other stress reduction activities practiced by respondents (freetext option), and the self-reported efficacy of such activities, categorised.

Social Support. The single item measure of social support (SIMSS) was employed to determine the number of people that provided support to participants. This item was developed by Blake and McKay (1986) and is a predictor of morbidity among women [17]. Responses of 0 or 1 indicate a low tangible assistance; 2 or more indicate high tangible assistance. It has been used in multiple studies with cancer patients $[34,35]$.

Fatigue. The fatigue severity scale (FSS) consists of nine fatigue-related statements rated on a seven-point scale from "disagree" to "agree" [18]. It has good internal consistency, stability, and sensitivity to change over time and is frequently used to assess fatigue in MS populations [29, 36]. A mean score $\geq 4$ has been suggested as a cutoff to indicate clinically significant fatigue and has been used in several other studies [36-38].

Depression. The patient health questionnaire (PHQ-9) is a depression screening tool which has been validated in patients with MS [39]. The patient health questionnaire depression module short version (PHQ-2), utilised in our study, is a two-item version of the PHQ-9 which has shown good construct and criterion validity in a sample of 6000 patients, with a reported sensitivity of $83 \%$ and specificity of $92 \%$ for major depression with a score $\geq 3$ [19]. The PHQ2 can be complemented by the emotional subscore of the MSQOL-54.

Engagement. Four items are asked about engagement in OMS resources and other sources of information on lifestyle and MS, such as books, websites, or educational programs (freetext response).

2.3. Data Analysis. The statistical package for the social sciences (SPSS) version 20.0 was used to calculate statistics. Univariate analyses were performed and continuous data reported using mean $(95 \% \mathrm{CI})$ or median (IQR) and categorical data using number and percentage. Due to variation in item completion, analyses were calculated using item
TABLE 2: Classification of MS medication types.

\begin{tabular}{lc}
\hline $\begin{array}{l}\text { First generation disease modifying } \\
\text { drugs }\end{array}$ & Interferons \\
& Glatiramer acetate \\
\hline Second generation disease modifying & Cladribine \\
drugs & Daclizumab \\
& Dimethyl fumarate \\
& Fingolimod \\
& Ratuinimod \\
& Teriflunomide \\
& Natalizumab \\
\hline Chemotherapy or & Azathioprine \\
Cymmoshophosphamide \\
& Methotrexate \\
\hline IVIG or plasmapheresis & Mitoxantrone \\
\hline Generic drugs & Mycophenolate mofetil \\
\hline \multirow{2}{*}{ Steroids } & Immunoglobulins IVIG \\
& Plasmapheresis \\
\hline \multirow{2}{*}{ Symptom modifying drugs } & Low-dose naltrexone \\
& Minocycline \\
\hline
\end{tabular}

response as the denominator. Where possible, summary scores from validated tools were derived according to scoring instructions or as suggested in the literature. The following are explanations of how new variables and summary scores were derived for the purpose of this paper.

A planned variable, "disease activity," was derived from data reporting relapse rates (doctor diagnosed) for those with relapsing-remitting MS only. It was categorised as increasing, decreasing, or stable, where relapse rate in the preceding 12 months was higher, lower, or the same, respectively, as the 5year annualised relapse rate. For the purpose of this paper, conditions listed in the SCQ were summed to determine the proportion of participants that had one or more comorbidity. "Other" free-text responses will be categorised and reported in a future study along with reporting of the treatment and limitations relevant to each condition.

The MSQOL-54 was scored according to the scoring instructions with a set number of items required to be completed in order to give rise to the subscores, which in turn were required for calculation of the composite scores; hence, there was variability in the completion rates.

Cutoff scores were set as an aggregate score $\geq 3$ in the PHQ-2 to screen positive for major depression, and a mean score $\geq 4$ in the FSS to indicate clinically significant fatigue, as defined in the literature. To derive both of these summary scores, full item completion was required.

Based on recency of licensing and mode of action, the medications were grouped into seven categories (Table 2). Free-text responses for "other" medications were reviewed and recategorised into existing variables. 


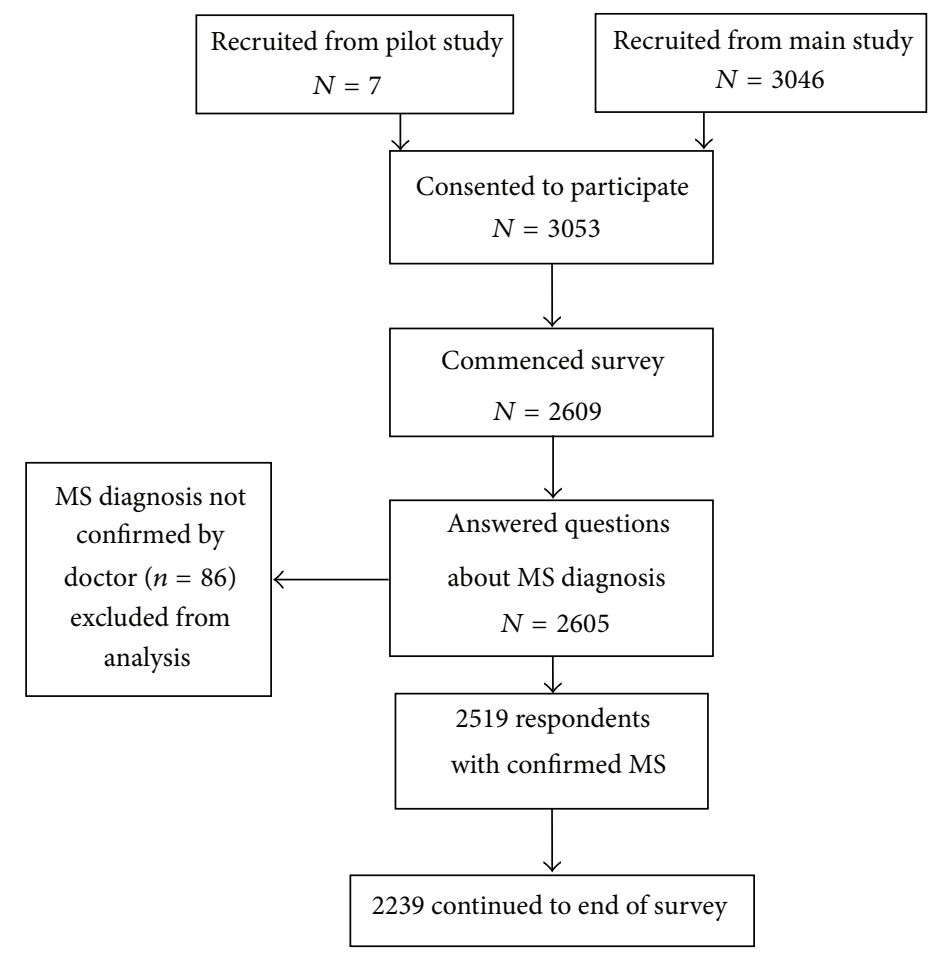

Figure 1: Participant study inclusion criteria.

\section{Results}

A total of 3053 participants consented to participate, seven of whom were pilot study participants, whose data were included in analysis. Of those that consented, 2519 had been formally diagnosed with MS and therefore met the criteria for study inclusion. 2518 of these provided contact details for followup (Figure 1). Of those with confirmed MS, 89\% continued to the end of the survey. Of the demographics and clinical characteristics items, there was an average item completion rate of $95 \%$.

3.1. Sociodemographic Data. The majority of respondents were women, comprising $82.2 \%$ of the sample (Table 3). Participants' ages ranged from 18 to 87, with a median age of 46 years (IQR 38-53). Country of residence spanned the globe, with participants originating from 77 countries and living in 57 different countries at the time of the survey (Table 10). Respondents residing in the United States, Australia, United Kingdom, New Zealand, and Canada comprised $88 \%$ of the study sample. The majority of respondents (61.1\%) were married, and over two-thirds had children. Around one-third were engaged in full-time work, whilst $23.4 \%$ had retired due to medical reasons or disability. Over half had completed a university bachelor's degree, and of these, $64.0 \%$ had also completed a postgraduate degree.

3.2. MS Diagnosis. A median of 13 years (IQR 7-21) had passed since participants first experienced symptoms of MS, whilst participants had formally been diagnosed with MS for a median of six years (IQR 3-12), with $45.0 \%$ having being diagnosed within the previous five years (Table 4 ). The median age at diagnosis was 37 (IQR 30-45). The majority of the sample had relapsing-remitting MS (61.0\%), which was also the most common subtype at time of diagnosis $(76.7 \%$; Table 5).

3.3. Disease Progression. The level of disability, as measured with the PDDS, was across all disability spectrums, but $31.7 \%$ reported having no symptoms or mild symptoms that return to normal after an attack: "normal" (Table 4). The median PDDS score was 3.0 (IQR 1.0-5.0). At the time of the survey, over one-quarter of participants were experiencing symptoms due to a recent relapse.

3.4. Relapse Rate. Over the previous 12 months, relapsingremitting participants self-reported an average of 1.09 relapses, and over the last five years, they self-reported an average of 0.97 relapses per year (Table 6). This was higher than relapse rate diagnosed by a doctor. For those with relapsing-remitting MS (with sufficient data; $n=1382$ ), based on diagnosis by a doctor, disease activity was decreasing for $42.0 \%$, increasing for $31.0 \%$, and remaining stable for $27.0 \%$.

3.5. Quality of Life, Depression, and Fatigue. Median summary scores from the MSQOL-54 were 68.4 (IQR 55.0-81.65) for the overall quality of life subscore, 59.2 (IQR 42.3-77.2) for the physical health composite, and 72.0 (IQR 51.2-84.1) for the mental health composite (Table 7). Using a score of 3 as a cutoff in the PHQ-2, nearly one-fifth of the sample screened positive for depression (Table 8). Respondents had a median 
TABLE 3: Characteristics of the study sample.

\begin{tabular}{|c|c|}
\hline Characteristic & $\begin{array}{c}\text { Number (\%) } \\
\text { (unless otherwise stated) }\end{array}$ \\
\hline \multicolumn{2}{|l|}{ Gender } \\
\hline Male & $413 / 2318(17.8)$ \\
\hline Female & $1905 / 2318(82.2)$ \\
\hline \multicolumn{2}{|l|}{ Age in 2012 (years) } \\
\hline $18-29$ & $124 / 2443(5.1)$ \\
\hline $30-39$ & $621 / 2443(25.4)$ \\
\hline $40-49$ & $794 / 2443(32.5)$ \\
\hline $50-59$ & $656 / 2443(26.9)$ \\
\hline $60-69$ & $231 / 2443(9.5)$ \\
\hline$>70$ & $17 / 2443(0.7)$ \\
\hline \multicolumn{2}{|l|}{ Country of location } \\
\hline USA & $827 / 2518(32.9)$ \\
\hline Australia & $649 / 2518(25.8)$ \\
\hline UK & $416 / 2518(16.5)$ \\
\hline $\mathrm{NZ}$ & $216 / 2518(8.6)$ \\
\hline Canada & $107 / 2518(4.2)$ \\
\hline Other* & $303 / 2518(12.2)$ \\
\hline \multicolumn{2}{|l|}{ Country of birth } \\
\hline USA & $790 / 2510(31.5)$ \\
\hline Australia & $518 / 2510(20.6)$ \\
\hline $\mathrm{UK}$ & $502 / 2510(20.0)$ \\
\hline $\mathrm{NZ}$ & $174 / 2510(6.9)$ \\
\hline Canada & $111 / 2510(4.4)$ \\
\hline Other $^{\dagger}$ & $415 / 2510(16.5)$ \\
\hline \multicolumn{2}{|l|}{ Marital status } \\
\hline Married & $1511 / 2475(61.1)$ \\
\hline Single & $359 / 2475(14.5)$ \\
\hline Cohabitating/partnered & $313 / 2475(12.6)$ \\
\hline Separated/divorced & $262 / 2475(10.6)$ \\
\hline Widowed & $30 / 2475(1.2)$ \\
\hline \multicolumn{2}{|l|}{ Family status } \\
\hline No children & $767 / 2477(31.0)$ \\
\hline One or more biological children & $1644 / 2466(66.7)$ \\
\hline One or more step children & $239 / 2466(9.7)$ \\
\hline No. of children^, median (IQR) & $2(0-2)$ \\
\hline \multicolumn{2}{|l|}{ Employment status } \\
\hline Employed full time & $807 / 2508(32.2)$ \\
\hline Employed part time & $526 / 2508(21.0)$ \\
\hline Stay at home parent/carer & $191 / 2508(7.6)$ \\
\hline Student full time & $57 / 2508(2.3)$ \\
\hline Unemployed $^{\ddagger}$ & $203 / 2508(8.1)$ \\
\hline Retired due to age & $79 / 2508(3.1)$ \\
\hline $\begin{array}{l}\text { Retired due to medical reasons or } \\
\text { disability }\end{array}$ & $588 / 2508(23.4)$ \\
\hline Other & $57 / 2508(2.3)$ \\
\hline
\end{tabular}

TABle 3: Continued.

\begin{tabular}{lc}
\hline Characteristic & $\begin{array}{c}\text { Number (\%) } \\
\text { (unless otherwise stated) }\end{array}$ \\
\hline Education status & \\
No formal schooling & $3 / 2504(0.1)$ \\
Primary school & $55 / 2504(2.2)$ \\
Secondary school & $570 / 2504(22.8)$ \\
Vocational training & $405 / 2504(16.2)$ \\
Bachelor's degree & $897 / 2504(35.8)$ \\
Postgraduate degree & $574 / 2504(22.9)$ \\
\hline
\end{tabular}

${ }^{*}$ Includes 72 other countries.

${ }^{\dagger}$ Includes 52 other countries.

${ }^{\wedge}$ Includes biological and step children.

${ }^{\ddagger}$ Collapsed from unemployed: seeking work/not seeking work.

TABLE 4: Diagnostic characteristics and level of disability.

\begin{tabular}{lc}
\hline & Number $(\%)$ \\
\hline Number of years since diagnosis & \\
$<1-5$ & $1107 / 2459(45.0)$ \\
$6-10$ & $577 / 2459(23.5)$ \\
$11-15$ & $393 / 2459(16.0)$ \\
$16-20$ & $186 / 2459(7.6)$ \\
$21-25$ & $98 / 2459(4.0)$ \\
$26-30$ & $48 / 2459(2.0)$ \\
$>30$ & $50 / 2459(2.0)$ \\
Disability (PDDS) & \\
Normal & $734 / 2314(31.7)$ \\
Mild disability & $352 / 2314(15.2)$ \\
Moderate disability & $170 / 2314(7.3)$ \\
Gait disability & $373 / 2314(16.1)$ \\
Early cane & $265 / 2314(11.5)$ \\
Late cane & $175 / 2314(7.6)$ \\
Bilateral support & $139 / 2314(6.0)$ \\
Wheelchair/scooter & $103 / 2314(4.5)$ \\
Bedridden & $3 / 2314(0.1)$ \\
Currently experiencing symptoms due to a & \\
recent relapse* & \\
Yes & \\
No & \\
Unsure & \\
\hline Definition of relapse provided to participants. & $1455 / 2429(59.9)$ \\
\hline & \\
\hline & \\
\hline & \\
\hline
\end{tabular}

overall score on the FSS of 4.9 (IQR 3.2-6.1), and 65.7\% (95\% CI 63.7-67.7) screened positive for clinically significant fatigue.

3.6. Health and Lifestyle. The following variables are a snapshot of participant responses and not comprehensive of all variables examined; these will be examined in greater detail in subsequent papers. $68.4 \%$ of participants reported having one or more of the listed comorbidities in the SCQ. At the time of the survey, $51.4 \%$ of respondents were taking a first or second 
TABle 5: Diagnosed subtype of MS.

\begin{tabular}{|c|c|c|c|c|c|c|}
\hline & Benign & $\begin{array}{l}\text { Relapsing- } \\
\text { remitting }\end{array}$ & $\begin{array}{c}\text { Primary } \\
\text { progressive }\end{array}$ & $\begin{array}{l}\text { Secondary } \\
\text { progressive }\end{array}$ & $\begin{array}{l}\text { Progressive } \\
\text { relapsing }\end{array}$ & Unsure/other \\
\hline $\begin{array}{l}\text { Type of MS first diagnosed with } \\
\text { number }(\%)\end{array}$ & $99 / 2455(4.0)$ & $1880 / 2455(76.6)$ & $157 / 2455(6.4)$ & $47 / 2455$ (1.9) & $14 / 2455(0.6)$ & $258 / 2455(10.5)$ \\
\hline $\begin{array}{l}\text { Type of MS currently diagnosed } \\
\text { with number (\%) }\end{array}$ & $101 / 2460(4.1)$ & $1500 / 2460(61.0)$ & $184 / 2460(7.5)$ & $287 / 2460(11.7)$ & $47 / 2460(1.9)$ & $341 / 2460(13.9)$ \\
\hline
\end{tabular}

TABLE 6: Relapse rate for relapsing-remitting participants.

\begin{tabular}{|c|c|c|c|c|c|c|}
\hline & \multicolumn{3}{|c|}{ Self-diagnosed relapse rate } & \multicolumn{3}{|c|}{ Doctor-diagnosed relapse rate } \\
\hline & $n$ & Mean $(95 \% \mathrm{CI})$ & Median (IQR) & $n$ & Mean $(95 \% \mathrm{CI})$ & Median (IQR) \\
\hline $\begin{array}{l}\text { Number of relapses over last } 12 \\
\text { months }^{*}\end{array}$ & $1475 / 1500$ & $1.09(1.01-1.17)$ & $1(0.0-2.0)$ & $1456 / 1500$ & $0.73(0.67-0.78)$ & $0(0.0-0.1)$ \\
\hline $\begin{array}{l}\text { Number of relapses over last } 5 \text { years, } \\
\text { annualised* }\end{array}$ & $1409 / 1500$ & $0.97(0.92-1.03)$ & $0.67(0.4-1.2)$ & $1399 / 1500$ & $0.66(0.62-0.70)$ & $0.5(0.2-1.0)$ \\
\hline
\end{tabular}

${ }^{*}$ Participants with relapsing-remitting MS.

TABLE 7: MSQOL summary scores.

\begin{tabular}{|c|c|c|c|c|}
\hline Summary score & $n$ (missing) & Distribution (Kolmogorov) & Mean $(95 \% \mathrm{CI})$ & Median (IQR) \\
\hline Overall quality of life subscore & $2275(244)$ & 0.00 & $66.9(66.1-67.7)$ & $68.4(55.0-81.7)$ \\
\hline Physical health composite & $1944(575)$ & 0.00 & $59.1(58.1-60.0)$ & $59.2(42.3-77.2)$ \\
\hline Mental health composite & $2222(297)$ & 0.00 & $66.7(65.8-67.6)$ & $72.0(51.2-84.1)$ \\
\hline
\end{tabular}

TABLE 8: Depression and fatigue screening.

\begin{tabular}{lccc}
\hline & Cutoff & Positive, number (\%, 95\% CI) & Negative, number (\%, 95\% CI) \\
\hline Depression screen (PHQ-2) & Negative $<$ 3; positive $\geq 3$ & $431 / 2231(19.3,17.7-21.0)$ & $1800 / 2231(80.7,79.0-82.3)$ \\
Fatigue (FSS) mean score & Negative $<$ 4; positive $\geq 4$ & $1408 / 2143(65.7,63.7-67.7)$ & $735 / 2143(34.3,32.3-36.3)$ \\
\hline
\end{tabular}

TABLE 9: Comparison of data with NARCOMS and MSBase registries.

\begin{tabular}{lccc}
\hline & HOLISM & NARCOMS [22] & MSBase [45] \\
\hline Female (\%) & 82.2 & 74.9 & 71.5 \\
Age at diagnosis (years) & 37.0 (median) & 36.9 (mean) & $32.2($ mean) \\
Age at symptom onset (years) & 31.0 (median) & 32.4 (mean) & Data not provided \\
Age at enrolment (years) & 46.0 (median) & 42.8 (mean) & 42.7 (mean) \\
Disease duration at enrolment (years) & 6.0 (median) & Data not provided & 10.4 (mean) \\
\hline
\end{tabular}

generation DMD. According to the single item measure of social support, the majority (59.5\%) had 2-5 people in their life that they could count on in times of difficulty, but $5.3 \%$ of the sample had no one. $38.0 \%$ of respondents did not consume dairy products, $26.7 \%$ did not consume meat products, and $21.5 \%$ consumed neither meat nor dairy. $11.7 \%$ were current smokers. Over two-thirds (67.0\%) intentionally exposed themselves to the sun to try to raise their vitamin D levels, and $82.3 \%$ took vitamin D supplements. Nearly twothirds of respondents (64.3\%) took omega-3 supplements. Meditation practice was undertaken at least once per week by 676 respondents $(30.0 \%)$.

\section{Discussion}

This is the first cross-sectional study examining health and lifestyle behaviours in a large international sample of people with MS using web 2.0 platforms. Our results suggest that the online MS community is a unique sample to study. The proportion of women that participated is an overrepresentation from the estimated incidence of 1.8 female cases for every male [40]. Studies show that women are more likely to participate in online research [41], which may explain this finding. The age range in our sample suggests that engagement with online resources or research is not exclusively for 
TABle 10: Country of residence.

\begin{tabular}{|c|c|}
\hline Country & $n$ \\
\hline Armenia & 1 \\
\hline Australia & 649 \\
\hline Austria & 2 \\
\hline Belgium & 5 \\
\hline Brazil & 7 \\
\hline Bulgaria & 1 \\
\hline Canada & 107 \\
\hline China & 1 \\
\hline Croatia & 7 \\
\hline Cyprus & 1 \\
\hline Czech Republic & 2 \\
\hline Denmark & 10 \\
\hline Estonia & 2 \\
\hline Finland & 4 \\
\hline France & 11 \\
\hline Gibraltar & 2 \\
\hline Guam & 1 \\
\hline Germany & 29 \\
\hline Greece & 12 \\
\hline Iceland & 2 \\
\hline India & 3 \\
\hline Indonesia & 1 \\
\hline Iran & 1 \\
\hline Ireland & 36 \\
\hline Israel & 2 \\
\hline Italy & 6 \\
\hline Kuwait & 1 \\
\hline Lebanon & 1 \\
\hline Luxembourg & 1 \\
\hline Malta & 2 \\
\hline Mexico & 3 \\
\hline Namibia & 1 \\
\hline Netherlands & 28 \\
\hline New Zealand & 216 \\
\hline Norway & 13 \\
\hline Philippines & 2 \\
\hline Poland & 2 \\
\hline Portugal & 6 \\
\hline Puerto Rico & 3 \\
\hline Qatar & 2 \\
\hline Romania & 4 \\
\hline Russian Federation & 2 \\
\hline Saudi Arabia & 2 \\
\hline Serbia & 2 \\
\hline Singapore & 2 \\
\hline Slovakia & 4 \\
\hline Slovenia & 2 \\
\hline South Africa & 30 \\
\hline
\end{tabular}

TABle 10: Continued.

\begin{tabular}{lc}
\hline Country & $n$ \\
\hline Spain & 9 \\
Sweden & 17 \\
Switzerland & 8 \\
Syria & 1 \\
Trinidad and Tobago & 1 \\
Turkey & 1 \\
United Arab Emirates & 4 \\
United Kingdom & 416 \\
United States & 827 \\
\hline
\end{tabular}

young, technology-savvy individuals but rather is embraced by all age groups. The majority of participants in our study are highly educated, with a significant number having completed one or more tertiary degrees. This has important implications because it is well established that there is a strong gradient for education and health behaviour and health status [42]. More educated patients are more likely to have a higher level of health literacy and have the resources to seek out, understand, and apply information about prevention and treatment for their condition [42], including use of the internet. Among people with MS, a higher level of education is associated with greater involvement in health care [43] and greater healthrelated quality of life [44].

In general, participants of this study had been diagnosed recently and had a low level of disability. This concurs with results from a self-enrolling online registry-NARCOMSthat reported one-third of their participants enrolled within two years of diagnosis and also had a median disability score of $3(1-5)$ on the PDDS [22]. Compared to the MSBase international registry (which is physician enrolled) with over 11,000 participants from 26 countries, in general the participants in our study were older at enrolment, were diagnosed at an older age, and had a shorter disease duration at enrolment [45] (Table 9). It is possible that patients who are recently diagnosed seek out information and support through online communities early in the illness and may be more motivated to contribute to research in the hope that it will offer some new evidence for the successful treatment of their condition.

It has been noted that clinical outcome measures of relapse rate and disability are insufficient alone to measure the impact of MS as they do not reflect patients' experiences of the disease [46]. Measures of health-related quality of life, fatigue, and depression are integral to gain a broader picture of the complex, multifaceted nature of the disease. Around one-fifth of our sample screened positive for depression. Depression commonly affects people with MS, and the prevalence rate in our sample is similar to that of Patten et al. (2003), who reported a 12-month prevalence of major depression in 26\% of their MS sample aged 18-45 [47]. A review of studies on depression in people with MS found that lifetime prevalence rates of about $40-50 \%$ and 12 -month prevalence rates of around $20 \%$ are commonly reported [48]. Fatigue is known to be one of the most debilitating, but poorly 
understood symptoms of MS [36]. Our data indicate that a significant proportion of MS participants have clinically significant fatigue, but the median overall score was lower than that reported with another large cohort [38]. Further analysis of the data will be undertaken to investigate the relationship between quality of life, depression, fatigue, and other variables in the study.

Wide-ranging health and lifestyle behaviours have not been studied extensively among people with MS [49]. A surprising number of participants in our study reported undertaking health and lifestyle behaviours not commonly observed among the general community and not previously reported with an MS sample, to our knowledge. This included diets containing no meat or dairy products, a high intake of omega-3 and vitamin D supplementation, lower smoking rates, and meditation practice, among other lifestyle modifications. Other studies have demonstrated high use of nonpharmacological therapies among people with MS [50-52], but the adoption of dietary practices, meditation, and vitamin $\mathrm{D}$ and omega-3 supplementation appear to be higher in our sample than that of a large cohort in Nordic countries [50]. Such healthy lifestyle behaviours have previously been suggested to modify the risk of disease progression in MS [3, 5$8,53-55]$, indicating that future analyses of this dataset should enable important new findings on the effect of such riskmodifying behaviours on MS and its associated symptoms.

The MS sample described appear to be a highly engaged and proactive group of patients. This is evidenced by the method of recruitment which was self-selecting from patients utilising online resources. The preliminary data suggests that a significant number in this sample have adopted lifestyle changes, much of which they would have learned about through self-directed learning beyond the clinical setting, and which demands a great deal of self-efficacy and commitment. A surprisingly large proportion of people continued to the end of the survey despite its considerable length. This was likely aided by the fact that participants could exit and return to the survey at their leisure. The large sample size and high item completion rate might indicate that the online MS community is motivated to contribute to novel research. Much of the feedback the research team received through the survey, emails, phone calls, and online comments was very positive. Participants expressed a desire for more research exploring lifestyle factors. Personal empowerment is key to successful adoption of healthful practices; people with MS who show increased levels of activation or self-efficacy also demonstrate positive changes in their self-management behaviours [56], self-reported improvements in health status [57], greater patient satisfaction, and improved quality of life [58].

Recruiting participants through web 2.0 platforms results in rapid access to a heterogeneous sample in a highly costeffective way and may invite contribution from previously hidden populations [41]. Engagement with online communities is becoming increasingly common with the advent of online platforms such as PatientsLikeMe, which encourages people to share their health information for the benefit of others [59]. However, recruiting participants through online methods is not without challenges. Firstly, it is possible for people to conceal their identity. This can be helpful when conducting surveys because anonymity may encourage more honest responses and greater disclosure [60]. The disadvantage however is difficulty in verifying the diagnosis of participants in the absence of clinician or medical record confirmation. To improve accuracy of diagnosis in our study, questions were asked regarding diagnostic procedures, and an additional section was included for people with an unconfirmed diagnosis, such as clinically isolated syndrome (CIS). This enabled everyone to take part, whilst maintaining separate analysis. The NARCOMS registry also utilises selfenrolment, and a validation study confirmed a self-reported diagnosis of MS in 98.7\% (SD \pm 1.3 ) of cases [61]. This suggests that it is unlikely that people without a formal diagnosis of MS would take part in the study, although a validation study looking at a sample of the data would significantly improve the reliability of diagnosis. Survey completion rate was high; however, around $15 \%$ of participants dropped out at the contact details section. Removing the need for contact details might have improved the overall response rate; however, this would have prevented followup. It is also possible that there will be challenges associated with retention of study participants in follow-up surveys. Due to the international nature of the study and large sample size, only email reminders will be a feasible method of contact. Varied online engagement strategies will be necessary to maximise the response rate at followup. It is worth noting that many of the challenges associated with online surveys are similar to those that arise when conducting mail-outs of selfreporting questionnaires with large registries [60].

Although participants in 57 countries took part in the survey, the majority were residing in western countries where English is the primary language. This is likely a direct reflection of the sources of recruitment used by the researchers, which were mostly limited to English language, while the survey itself demanded a high level of literacy. Severe physical disability may have prevented some people with MS from taking part as they may not have been able to complete the survey without assistance. The fact that some participants were directly recruited through a website and associated forums promoting lifestyle modification may have resulted in the participation of individuals with an interest in, and more inclined to undertake, holistic disease management. As such, the findings from this study may not be generalisable to the global online MS community.

When making a decision about which items to include in the survey, serious consideration was given to the time burden placed on participants, given that the survey intended to cover many different domains. Although validated tools were used where possible, and researcher-devised items were carefully constructed, with the survey piloted with a small group, there are a number of limitations to the survey. Firstly, the validated tools have not all been tested for validity and reliability across diverse MS samples. Different cultural understandings of health mean that the use of western terminology and concepts of health with a culturally diverse sample may have allowed bias. It is also unclear whether these validated tools have previously been tested in an online survey format. It is also possible that the study was more likely to select 
participants with a higher level of socioeconomic status due to the method of recruiting through web 2.0 platforms. Socioeconomic status of participants was not measured in the questionnaire. This is because of the international nature of the survey and difficulty correlating data across regions.

A significant proportion of participants reported experiencing symptoms related to a recent relapse. It may be difficult for patients to distinguish between enduring relapse symptoms and a permanent progression of disability. This has the potential to impact other outcome variables, and future analyses will need account for this. All data were self-reported, which can lead to potential sources of bias due to over- or underreporting. This needs to be considered particularly in light of historic reporting of events which can be limited by poor recall, such as the number of relapses in the preceding five years, or poor knowledge, such as the number of lesions or vitamin D level. We were not able to verify the accuracy of these responses. Validation through medical records or physician's report would significantly increase the reliability of self-reported data. Consideration will be given to the limitations of data reliant on self-report that may be used in future analyses. Despite these limitations, some selfreported data in MS study participants have previously been found to be a reliable measure of outcomes [62, 63]. The importance of the patient perspective in measuring health outcomes has become, and continues to remain, a major focus of clinical and epidemiological research.

\section{Conclusion}

Increasingly, web 2.0 platforms are being embraced by patients and researchers alike, with the shared goal of improving patient-centred health outcomes. The characteristics described above suggest this online MS community recruited to our study is a heterogeneous and unique group who appear actively engaged and keen to contribute to research on health and lifestyle behaviour. Although there are several limitations to conducting research with online communities, this method provides efficient and rapid access to a large sample of people with MS. This study provides a sound platform to undertake exploratory analyses of lifestyle variables that have not previously been examined in such detail. The dataset will provide an important opportunity for novel research into lifestyle and health behaviours and their potential impact on MS outcomes over time.

\section{Acknowledgments}

The authors thank all the participants for taking part in the survey and the Bloom Foundation for funding the project.

\section{References}

[1] R. A. Marrie, "Environmental risk factors in multiple sclerosis aetiology," The Lancet Neurology, vol. 3, no. 12, pp. 709-718, 2004.

[2] P. Flachenecker and K. Stuke, "National MS registries," Journal of Neurology, vol. 255, no. 6, pp. 102-108, 2008.
[3] M. B. D’Hooghe, G. Nagels, V. Bissay, and J. de Keyser, "Modifiable factors influencing relapses and disability in multiple sclerosis," Multiple Sclerosis, vol. 16, no. 7, pp. 773-785, 2010.

[4] R. A. Marrie, "Demographic, genetic, and environmental factors that modify disease course," Neurologic Clinics, vol. 29, no. 2, pp. 323-341, 2011.

[5] G. Jelinek, Taking Control of Multiple Sclerosis: Natural and Medical Therapies to Prevent Its Progression, Fleetbooks, Lancaster, UK, 2005.

[6] E. J. Hadgkiss, G. A. Jelinek, T. J. Weiland et al., "Health-related quality of life outcomes at 1 and 5 years after a residential retreat promoting lifestyle modification for people with multiple sclerosis," Neurological Sciences, vol. 34, no. 2, pp. 187-195, 2013.

[7] G. Jelinek, Overcoming Multiple Sclerosis: An Evidence-Based Guide to Recovery, Allen and Unwin, Sydney, Australia, 2010.

[8] M. B. D. 'Hooghe, P. Haentjens, G. Nagels, and J. de Keyser, "Alcohol, coffee, fish, smoking and disease progression in multiple sclerosis," The European Journal of Neurology, vol. 19, no. 4, pp. 616-624, 2012.

[9] B. M. Kuehn, "Patients go online seeking support, practical advice on health conditions," Journal of the American Medical Association, vol. 305, no. 16, pp. 1644-1645, 2011.

[10] B. K. Lee, "Epidemiologic research and Web 2.0-the user-driven Web," Epidemiology, vol. 21, no. 6, pp. 760-763, 2010.

[11] C. Stromgren, "Community outreach through web resources: multiple sclerosis," Medical Reference Services Quarterly, vol. 21, no. 1, pp. 61-70, 2002.

[12] M. J. Hohol, E. J. Orav, and H. L. Weiner, "Disease steps in multiple sclerosis: a simple approach to evaluate disease progression," Neurology, vol. 45, no. 2, pp. 251-255, 1995.

[13] O. Sangha, G. Stucki, M. H. Liang, A. H. Fossel, and J. N. Katz, "The self-administered comorbidity questionnaire: a new method to assess comorbidity for clinical and health services research," Arthritis Care and Research, vol. 49, no. 2, pp. 156163, 2003.

[14] B. G. Vickrey, R. D. Hays, R. Harooni, L. W. Myers, and G. W. Ellison, "A health-related quality of life measure for multiple sclerosis," Quality of Life Research, vol. 4, no. 3, pp. 187-206, 1995.

[15] S. McKellar, P. Horsley, R. Chambers et al., "Development of the diet habits questionnaire for use in cardiac rehabilitation," Australian Journal of Primary Health, vol. 14, no. 3, pp. 43-47, 2008.

[16] C. L. Craig, A. L. Marshall, M. Sjöström et al., "International physical activity questionnaire: 12 -country reliability and validity," Medicine and Science in Sports and Exercise, vol. 35, no. 8, pp. 1381-1395, 2003.

[17] R. L. Blake and D. A. McKay, "A single-item measure of social supports as a predictor of morbidity," Journal of Family Practice, vol. 22, no. 1, pp. 82-84, 1986.

[18] L. B. Krupp, N. G. LaRocca, J. Muir-Nash, and A. D. Steinberg, "The fatigue severity scale. Application to patients with multiple sclerosis and systemic lupus erythematosus," Archives of Neurology, vol. 46, no. 10, pp. 1121-1123, 1989.

[19] K. Kroenke, R. L. Spitzer, and J. B. W. Williams, “The patient health questionnaire-2: validity of a two-item depression screener," Medical Care, vol. 41, no. 11, pp. 1284-1292, 2003.

[20] Australian Bureau of Statistics, "Australian standard classification of cultural and ethnic groups," 2012, http://www.abs.gov.au/ AUSSTATS/abs@.nsf/DetailsPage/1249.02011?OpenDocument. 
[21] M. J. Hohol, E. J. Orav, and H. L. Weiner, "Disease steps in multiple sclerosis: a longitudinal study comparing disease steps and EDSS to evaluate disease progression," Multiple Sclerosis, vol. 5, no. 5, pp. 349-354, 1999.

[22] R. A. Marrie, G. Cutter, T. Tyry, O. Hadjimichael, D. Campagnolo, and T. Vollmer, "Changes in the ascertainment of multiple sclerosis,” Neurology, vol. 65, no. 7, pp. 1066-1070, 2005.

[23] R. A. Marrie, G. Cutter, T. Tyry, T. Vollmer, and D. Campagnolo, "Does multiple sclerosis-associated disability differ between races?" Neurology, vol. 66, no. 8, pp. 1235-1240, 2006.

[24] O. Hadjimichael, T. Vollmer, and M. K. Oleen-Burkey, "Fatigue characteristics in multiple sclerosis: the North American Research Committee on Multiple Sclerosis (NARCOMS) survey," Health and Quality of Life Outcomes, vol. 6, article 100, 2008.

[25] L. Holper, M. Coenen, A. Weise, G. Stucki, A. Cieza, and J. Kesselring, "Characterization of functioning in multiple sclerosis using the ICF," Journal of Neurology, vol. 257, no. 1, pp. 103$113,2010$.

[26] A. Solari, G. Filippini, L. Mendozzi et al., "Validation of Italian multiple sclerosis quality of life 54 questionnaire," Journal of Neurology Neurosurgery and Psychiatry, vol. 67, no. 2, pp. 158$162,1999$.

[27] T. Yamamoto, K. Ogata, M. Katagishi et al., "Validation of the Japanese-translated version multiple sclerosis quality of life-54 instrument," Clinical Neurology, vol. 44, no. 7, pp. 417-421, 2004.

[28] C. Acquardo, L. Lafortune, and I. Mear, "Quality of life in multiple sclerosis: translation in French Canadian of the MSQoL-54," Health and Quality of Life Outcomes, vol. 1, article 70, 2003.

[29] M. P. Amato, G. Ponziani, F. Rossi, C. L. Liedl, C. Stefanile, and L. Rossi, "Quality of life in multiple sclerosis: the impact of depression, fatigue and disability," Multiple Sclerosis, vol. 7, no. 5, pp. 340-344, 2001.

[30] J. L. Wang, M. A. Reimer, L. M. Metz, and S. B. Patten, "Major depression and quality of life in individuals with multiple sclerosis," International Journal of Psychiatry in Medicine, vol. 30, no. 4, pp. 309-317, 2000.

[31] D. K. Tepavcevic, J. Kostic, I. D. Basuroski, N. Stojsavljevic, T. Pekmezovic, and J. Drulovic, "The impact of sexual dysfunction on the quality of life measured by MSQoL-54 in patients with multiple sclerosis," Multiple Sclerosis, vol. 14, no. 8, pp. 1131-1136, 2008.

[32] N. Stroud, C. Minahan, and S. Sabapathy, "The perceived benefits and barriers to exercise participation in persons with multiple sclerosis," Disability and Rehabilitation, vol. 31, no. 26, pp. 2216-2222, 2009.

[33] M. Weikert, R. W. Motl, Y. Suh, E. McAuley, and D. Wynn, "Accelerometry in persons with multiple sclerosis: measurement of physical activity or walking mobility?" Journal of the Neurological Sciences, vol. 290, no. 1-2, pp. 6-11, 2010.

[34] N. Reavley, J. F. Pallant, and A. Sali, "Evaluation of the effects of a psychosocial intervention on mood, coping, and quality of life in cancer patients," Integrative Cancer Therapies, vol. 8, no. 1, pp. 47-55, 2009.

[35] C. Koopman, B. Nouriani, V. Erickson et al., "Sleep disturbances in women with metastatic breast cancer," Breast Journal, vol. 8, no. 6, pp. 362-370, 2002.

[36] T. Smedal, A. G. Beiske, S. B. Glad et al., "Fatigue in multiple sclerosis: associations with health-related quality of life and physical performance," The European Journal of Neurology, vol. 18, no. 1, pp. 114-120, 2011.
[37] A. Lerdal, E. G. Celius, and T. Moum, "Fatigue and its association with sociodemographic variables among multiple sclerosis patients," Multiple Sclerosis, vol. 9, no. 5, pp. 509-514, 2003.

[38] R. A. Marrie, G. Cutter, T. Tyry, O. Hadjimichael, D. Campagnolo, and T. Vollmer, "Validation of the NARCOMS registry: fatique assessment," Multiple Sclerosis, vol. 11, no. 5, pp. 583-584, 2005.

[39] K. Sjonnesen, S. Berzins, K. M. Fiest et al., "Evaluation of the 9-item Patient Health Questionnaire (PHQ-9) as an assessment instrument for symptoms of depression in patients with multiple sclerosis," Postgraduate Medicine, vol. 124, no. 5, pp. 69-77, 2012.

[40] A. Alonso and M. A. Hernán, “Temporal trends in the incidence of multiple sclerosis: a systematic review," Neurology, vol. 71, no. 2, pp. 129-135, 2008.

[41] S. D. Rhodes, D. A. Bowie, and K. C. Hergenrather, "Collecting behavioural data using the world wide web: considerations for researchers," Journal of Epidemiology and Community Health, vol. 57, no. 1, pp. 68-73, 2003.

[42] D. M. Cutler and A. Lleras-Muney, "Education and health: evaluating theories and evidence," Working Paper No. 12352, National Bureau of Economic Research, Massachusetts, Mass, USA, 2006.

[43] L. Stepleman, M. C. Rutter, J. Hibbard, L. Johns, D. Wright, and M. Hughes, "Validation of the patient activation measure in a multiple sclerosis clinic sample and implications for care," Disability and Rehabilitation, vol. 32, no. 19, pp. 1558-1567, 2010.

[44] W. M. Hopman, H. Coo, C. M. Edgar, E. V. McBride, A. G. Day, and D. G. Brunet, "Factors associated with health-related quality of life in multiple sclerosis," The Canadian Journal of Neurological Sciences, vol. 34, no. 2, pp. 160-166, 2007.

[45] I. Kister, E. Chamot, G. Cutter et al., "Increasing age at disability milestones among MS patients in the MSBase Registry," Journal of the Neurological Sciences, vol. 318, no. 1-2, pp. 94-99, 2012.

[46] D. Miller, R. A. Rudick, and M. Hutchinson, "Patient-centered outcomes translating clinical efficacy into benefits on healthrelated quality of life," Neurology, vol. 74, supplement 3, pp. S24S35, 2010.

[47] S. B. Patten, C. A. Beck, J. V. A. Williams, C. Barbui, and L. M. Metz, "Major depression in multiple sclerosis: a populationbased perspective," Neurology, vol. 61, no. 11, pp. 1524-1527, 2003.

[48] R. J. Siegert and D. A. Abernethy, "Depression in multiple sclerosis: a review," Journal of Neurology, Neurosurgery and Psychiatry, vol. 76, no. 4, pp. 469-475, 2005.

[49] R. A. Marrie, R. Horwitz, G. Cutter, T. Tyry, D. Campagnolo, and T. Vollmer, "High frequency of adverse health behaviors in multiple sclerosis," Multiple Sclerosis, vol. 15, no. 1, pp. 105-113, 2009.

[50] L. Skovgaard, P. H. Nicolajsen, E. Pedersen et al., "Use of complementary and alternative medicine among people with multiple sclerosis in the Nordic countries," Autoimmune Diseases, vol. 2012, Article ID 841085, 13 pages, 2012.

[51] S. Schwarz, C. Knorr, H. Geiger, and P. Flachenecker, "Complementary and alternative medicine for multiple sclerosis," Multiple Sclerosis, vol. 14, no. 8, pp. 1113-1119, 2008.

[52] L. Shinto, V. Yadav, C. Morris, J. A. Lapidus, A. Senders, and D. Bourdette, "Demographic and health-related factors associated with complementary and alternative medicine (CAM) use in multiple sclerosis," Multiple Sclerosis, vol. 12, no. 1, pp. 94-100, 2006. 
[53] G. A. Jelinek and C. S. Hassed, "Managing multiple sclerosis in primary care: are we forgetting something?” Quality in Primary Care, vol. 17, no. 1, pp. 55-61, 2009.

[54] M. P. M. Li, G. A. Jelinek, T. J. Weiland et al., "Effect of a residential retreat promoting lifestyle modifications on healthrelated quality of life in people with multiple sclerosis," Quality in Primary Care, vol. 18, no. 6, pp. 379-389, 2010.

[55] R. H. Dworkin, D. Bates, J. H. D. Millar, and D. W. Paty, "Linoleic acid and multiple sclerosis: a reanalysis of three double-blind trials," Neurology, vol. 34, no. 11, pp. 1441-1445, 1984.

[56] J. H. Hibbard, E. R. Mahoney, R. Stock, and M. Tusler, "Do increases in patient activation result in improved self-management behaviors?" Health Services Research, vol. 42, no. 4, pp. 1443-1463, 2007.

[57] A. Riazi, A. J. Thompson, and J. C. Hobart, "Self-efficacy predicts self-reported health status in multiple sclerosis," Multiple Sclerosis, vol. 10, no. 1, pp. 61-66, 2004.

[58] D. M. Mosen, J. Schmittdiel, J. Hibbard, D. Sobel, C. Remmers, and J. Bellows, "Is patient activation associated with outcomes of care for adults with chronic conditions?" Journal of Ambulatory Care Management, vol. 30, no. 1, pp. 21-29, 2007.

[59] P. Wicks, M. Massagli, J. Frost et al., "Sharing health data for better outcomes on patientslikeme," Journal of Medical Internet Research, vol. 12, no. 2, article e19, 2010.

[60] C. Mendelson, "Recruiting participants for research from online communities," Computers Informatics Nursing, vol. 25, no. 6, pp. 317-323, 2007.

[61] R. A. Marrie, G. Cutter, T. Tyry, D. Campagnolo, and T. Vollmer, "Validation of the NARCOMS registry: diagnosis," Multiple Sclerosis, vol. 13, no. 6, pp. 770-775, 2007.

[62] S. M. Gold, H. Schulz, A. Mönch, K. H. Schulz, and C. Heesen, "Cognitive impairment in multiple sclerosis does not affect reliability and validity of self-report health measures," Multiple Sclerosis, vol. 9, no. 4, pp. 404-410, 2003.

[63] G. Ingram, E. Colley, Y. Ben-Shlomo et al., "Validity of patientderived disability and clinical data in multiple sclerosis," Multiple Sclerosis, vol. 16, no. 4, pp. 472-479, 2010. 


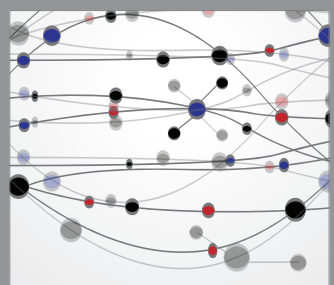

The Scientific World Journal
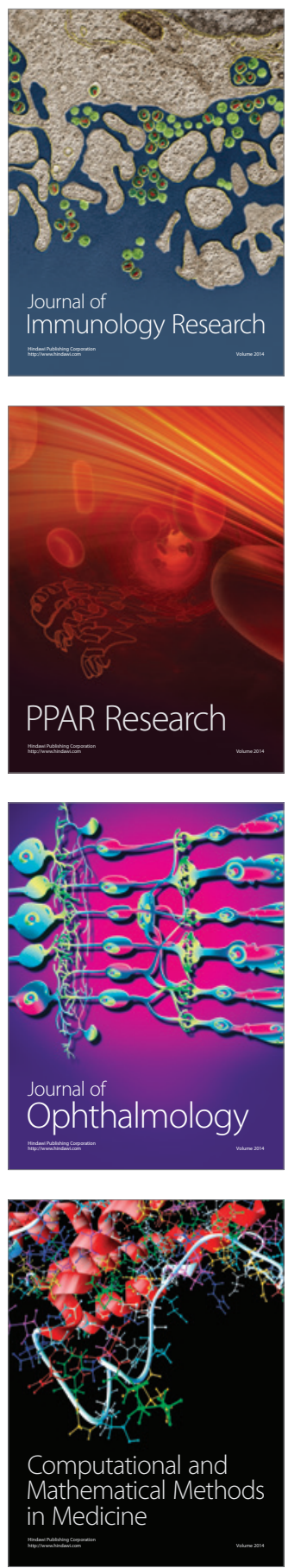

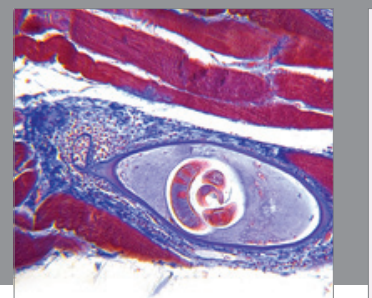

Gastroenterology

Research and Practice
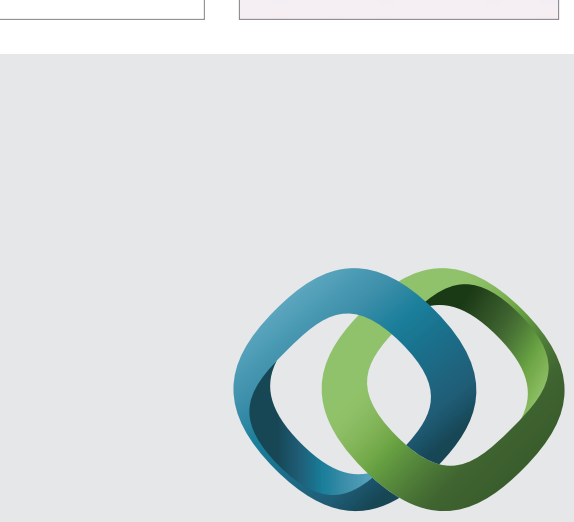

\section{Hindawi}

Submit your manuscripts at

http://www.hindawi.com
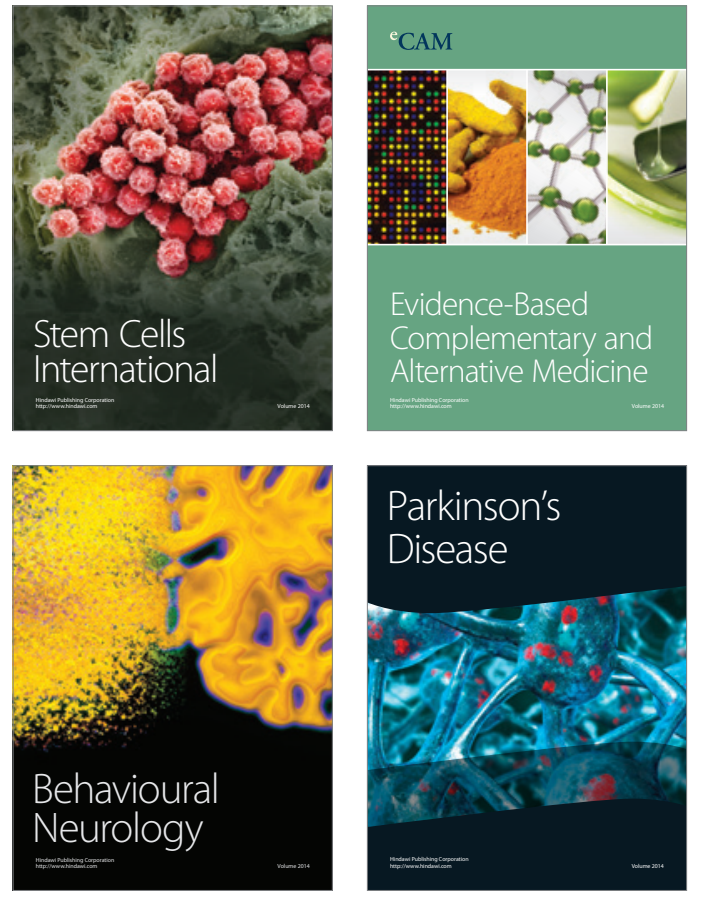
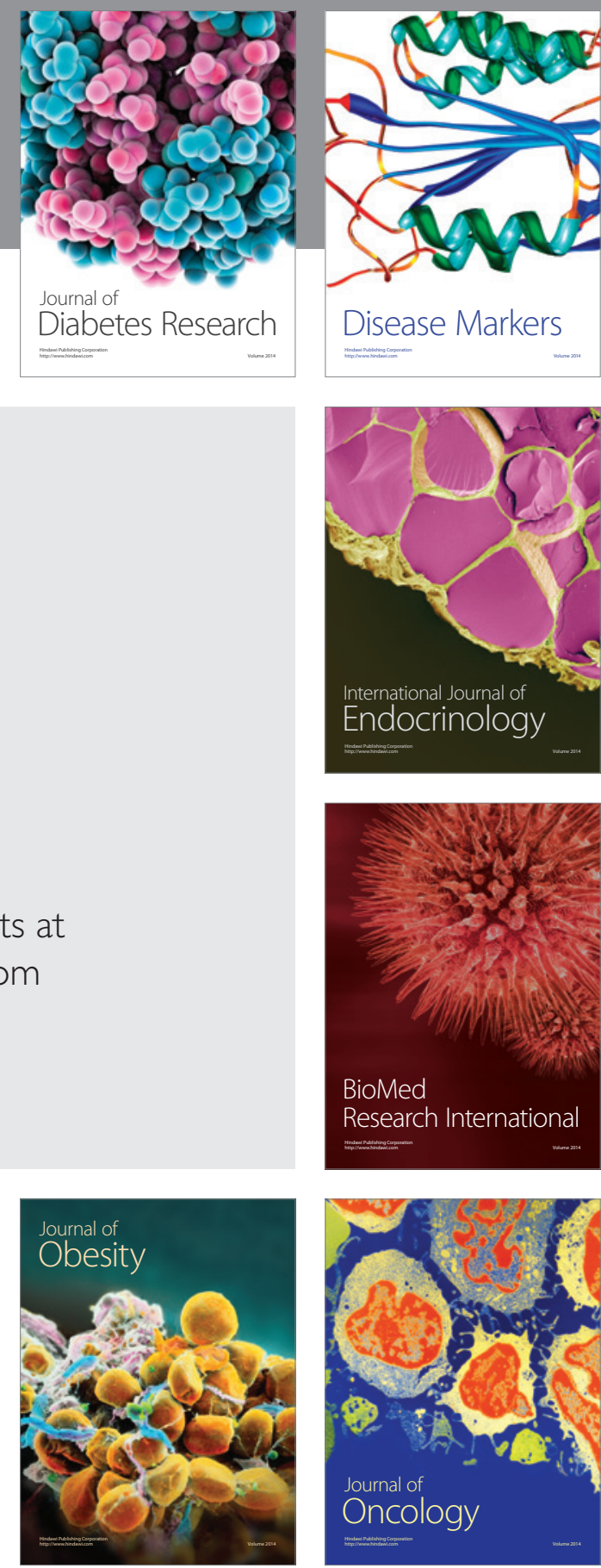

Disease Markers
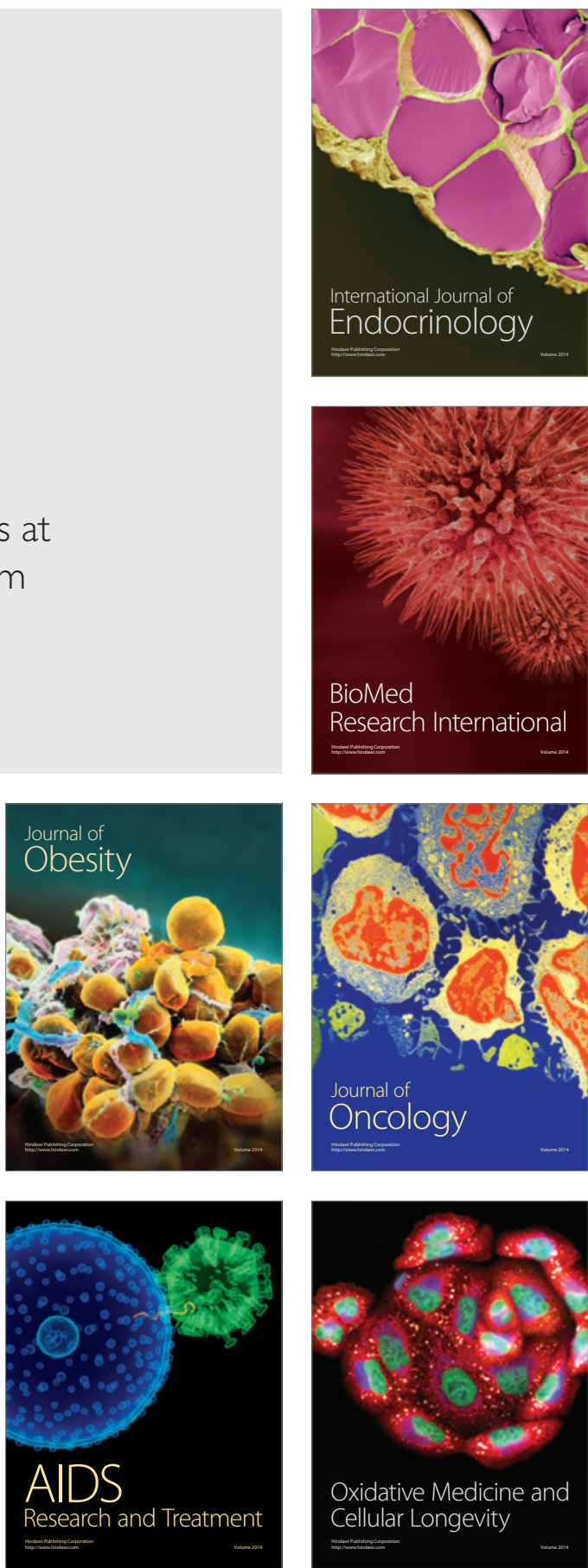